\title{
Potential of Cover Crops in Promoting Mycorrhizal Diversity and Soil Quality in Organic Farms
}

\author{
P. G. Soti ${ }^{1}$, Savannah $\operatorname{Rugg}^{1} \&$ Alexis Racelis ${ }^{1}$ \\ ${ }^{1}$ Department of Biology, University of Texas Rio Grande Valley, Edinburg, TX, USA \\ Correspondence: P. G. Soti, Agroecology and Resilient Food Systems, University of Texas Rio Grande Valley, \\ Edinburg, TX 78539, USA. Tel: 1-956-665-7915. E-mail: pushpa.soti@utrgv.edu
}

Received: May 14, 2016

Accepted: June 15, $2016 \quad$ Online Published: July 15, 2016

doi:10.5539/jas.v8n8p42

URL: http://dx.doi.org/10.5539/jas.v8n8p42

\begin{abstract}
Mycorrhizal fungi play a crucial role in agroecosystems with their ability to enhance nutrient and water uptake and aid in weeds and pest suppression. Mycorrhizal fungi have a symbiotic association with plants, one which is highly influenced by the interaction between soil and plant conditions. In this study, we analyzed the potential to increase the density and diversity of mycorrhizal fungi of using four different cover-crops: lablab (Lablab purpureus), sunn hemp (Crotalaria juncea), pearl millet (Pennisetum glaucum), and sudangrass (Sorghum drummondii). We examined changes in the density, diversity and structure of mycorrhizal fungi before and after planting the cover crops. Our results indicate that, while the diversity of mycorrhizal fungi was not influenced by the cover-crop type, different cover crops were associated with changes in the density and structure of mycorrhizal fungi. In addition, the cover-crop type also had an impact on the soil organic matter and nutrient status. Of the four we tested, sunn hempwas associated with higher rates of percent organic matter, abundance of mycorrhiza spores, and specific micronutrients, signaling multiple benefits as a warm season cover crop, especially in organic farms that aim to minimize chemical applications.
\end{abstract}

Keywords: cover crops, organic agriculture, mycorrhizal fungi, soil organic matter, subtropics, soil degradation

\section{Introduction}

Soil microbial communities play a very important role in improving soil health and plant productivity through recycling of nutrients and increasing nutrient availability in agroecosystems. For example, mycorrhizal fungi and plant growth-promoting rhizobacteria can enhance plants' tolerance to adverse environmental stresses via plant growth promotion and induced resistance (Pineda et al., 2010). Mycorrhizal fungi are especially important in organic farming as they act as natural fertilizers enhancing nutrient uptakeand providing resistance against drought and soil pathogens. Various studies have demonstrated that mycorrhizal symbiosis is crucial in nutrient deficient soils (Marschner \& Dell, 1994; Johnson et al., 2010; Soka \& Ritchie, 2014), where for examplemycorrhizal fungi can contribute to up to $90 \%$ of plant P demand (Van Der Heijden et al., 2006). As a result, agroecosystems with high diversity and abundance of mycorrhizal fungi often result in better crop performance and increased productivity (Khade \& Rodrigues, 2009) and improved agroecosystem services such as soil aggregation, improved soil structure and carbon sequestration (Barrios, 2007; Van Der Heijden \& Scheublin, 2007). Mycorrhizal fungi are formed at the interface between soil and plant roots and highly sensitive to changes in the plant or soil conditions. Thus, fallow periods are especially detrimental to mycorrhizal fungi as they depend on the host plants for their nutrition Cheeke et al. (2012).

Improvement of crop growth by mycorrhizal fungi association can be enhanced by increasing the effectiveness of indigenous fungi (Miller et al., 1995; Kabir \& Koide, 2000). However, there has been relatively little attention given to understanding how to enhance mycorrhizal fungi to benefit cash crops, especially in the southern US, where farmers deal with warmer climates associated with high rates of decomposition. In the Lower Rio Grande Valley (LRGV) of deep south Texas, farmers have to also contend with highly calcareous soils with low organic matter and high soil $\mathrm{pH}$ (Table 1). While indigenous mycorrhizal fungi may be prevalent, the availability of macro and micro nutrients is low. As such, finding ways to increase fungi colonization in this region may help increase farm productivity and sustainability.

Farmers in the LRGV frequently grow crops highly dependent on mycorrhizal fungi such as peppers and corn, following non mycorrhizal dependent brassica crops (Storz, 2011). Thus, growing mycorrhizal cover crops in 
rotation with these cash crops may help promote mycorrhizal fungi, so they can form associations with corps that depend on them. Cover crops are known to improve the mycorrhizal inoculum of the soil (Kabir \& Koide, 2000). However, there is very little information on cover crops in the LRGV. Furthermore, the USDA does not have any recommendations on cover crops for subtropical areas (Plant Zones 9-10). Given their benefits in nutrient uptake, mycorrhizal fungi can be of high value for the functioning and sustainability of agroecosystems, particularly in organic farms where choices of external inputs are limited. There are several commercial inoculants available, but generally are limited in diversity. In addition, and since commercial inoculants are usually not native to specific areas (especially in the southern US where there is a lack of options), these commercial varieties might not be well adapted to the farm conditions where they are applied. Thus, cover crops can be a cost effective and easy method to harness the benefits of extant mycorrhizal fungi. The objectives of this study were: to assess the effects of four different warm season cover crop candidates-lablab (Lablab purpureus), sunn hemp (Crotalaria juncea), pearl millet (Pennisetum glaucum), sudangrass (Sorghum drummondii)—on the spore density and diversity of mycorrhizal fungi, soil organic carbon and nutrient status, and soil organic matter and nutrients.

\section{Materials and Methods}

\subsection{Research Site}

We tested four different cover crops to analyze their ability to increase mycorrhizal fungi density and impact soil nutrients in a certified organic farm in Harlingen, Texas $\left(26^{\circ} 09^{\prime} 20^{\prime \prime} \mathrm{N}, 97^{\circ} 42^{\prime} 19^{\prime \prime} \mathrm{W}\right)$. We created ten $48 \times 110 \mathrm{ft}$ plots for the experiment in completely randomized design. The soil nutrient status of the farm at the beginning of the experiment (July, 2015) is given in Table 1. Initially, this site had high levels of calcium concentration ranging from $18913 \mathrm{ppm}$ to $22511 \mathrm{ppm}$, high soil $\mathrm{pH}$ and very low organic matter content, an environment not conducive for the microbial activity (Naidu \& Rengasamy, 1993). The soil texture was silty loam with very poor drainage, which is a common characteristic of soils in this region. The nutrient distribution along our field varied considerably, likely a result of the variation in the water drainage pattern in the field.

Table 1. Soil nutrient status (in ppm) at the beginning of the cover crops experiment

\begin{tabular}{llllll}
\hline & Pearl millet & Lablab & Sunn hemp & Sudangrass & Control \\
\hline Boron & 1.60 & 1.80 & 1.55 & 1.90 & 1.60 \\
Calcium & 20344 & 21024 & 20410 & 22511 & 18913 \\
Copper & 0.50 & 0.50 & 0.70 & 0.70 & 3.40 \\
Iron & 0.20 & 0.25 & 0.20 & 0.25 & 0.30 \\
Magnesium & 139 & 145.50 & 140 & 155 & 130 \\
Manganese & 15 & 17.25 & 15.95 & 21.70 & 20.40 \\
Nitrate & 25 & 19.50 & 17 & 19.50 & 18 \\
OM\% & 2.68 & 2.51 & 2.25 & 2.43 & 3.08 \\
pH & 8.00 & 8.05 & 8.10 & 8.05 & 8.00 \\
Phosphorus & 7 & 7.75 & 7.45 & 9.05 & 8.1 \\
Potassium & 442 & 512.50 & 479.50 & 554.50 & 350 \\
Sulfur & 196.20 & 211.95 & 218.95 & 220.25 & 236.80 \\
Zinc & 0.60 & 0.55 & 0.55 & 0.75 & 6.20 \\
\hline
\end{tabular}

\subsection{Cover Crops}

We selected four different cover crops (two legumes and two grasses, respectively) for this study: lablab (Lablab purpureus), sunn hemp (Crotalaria juncea), pearl millet (Pennisetum glaucum), and sudangrass (Sorghum drummondii). Seeds were purchased from different vendors and were approved for use in organic farms (sudangrass, pearl millet from Johnny's Select Seeds Winslow, ME; lablab and sunn hemp were purchased from Hancock Farm Seed Co., Dade City FL). The farm was previously planted with Brassica oleraceae (kale, a non-mycorrhizal crop). On July 7, 2015 we planted all the cover crops using a hand broadcaster. The cover crops were flood-irrigated two times the study period: two days after seeding and after four weeks. After 8 weeks the plants were tilled on September 3, 2015. 


\subsection{Soil Sample Collection and Analysis}

Four weeks after tilling the cover crops soil samples were collected from the plots and analyzed for mycorrhizal fungi spores and soil organic matter status. Three soil samples were collected from each plot with a soil corer (diameter $=2.5 \mathrm{~cm}$; AMS, American Falls, ID). Soil samples from each plot were mixed thoroughly to create a composite sample for each cover crop. A portion of soil samples were then stored in a $4{ }^{\circ} \mathrm{C}$ refrigerator until analysis. Soil samples for soil chemical analysis were air dried and ground in a mortar pestle and shipped in air tight containers to the Soil and Plant Tissue Testing Laboratory, University of Massachusetts (Amherst, MA). Soil organic matter was estimated by loss on ignition method and soil moisture was measured by the gravimetric method.

\subsection{Spore Extraction}

Mycorrhizal spores were extracted from soil by using a modified wet sieving and decanting technique Gerdemann and Nicolson (1963). Ten gram of soil was added to $500 \mathrm{ml}$ of water and mixed vigorously to separate the spores from soil aggregates. The soil mixture was then passed through a series of sieves and washed until the water flowing through the sieves was clear. The sievate retained on the sieves was washed and centrifuged with water to remove the organic debris. The pellet in the bottom was resuspended in a $50 \%$ sucrose solution, and centrifuged for one minute at 1600 RPM to separate the spores from denser soil components. Immediately after centrifugation, spores in the sucrose supernatant were washed into petri dishes for counting. The spores were counted under ZEISS Discovery V5 stereomicroscope. Spores collected from each treatment were grouped based on the color, size and shape. They were then observed under 100x magnification and identified to genus level following the International Culture Collection of VA Mycorrhizal Fungi (INVAM) based on the spore morphology (Schenck \& Pérez, 1988).

\subsection{Data Analysis}

Data was stored in an excel spreadsheet and analyzed with Statistical Analysis System (SAS, 2003). Difference in the soil nutrient status due to cover crops was calculated by subtracting the soil nutrient concentration at the beginning of the experiment from the soil nutrient concentration at the end of the experiment. Correlations between soil spore density and soil chemical and physical properties were done using Pearson correlations coefficients.

\section{Results}

\subsection{Mycorrhizal Fungi Spores}

Overall, all cover crop treatments had a positive effect on the mycorrhizal spore density compared to the control. Total spore density varied significantly among the different cover crop treatments, ranging from 52 to 187 spores per 10 grams of dry soil (Figure 1). Our results indicate that the mycorrhizal spore density was influenced by the cover crop identity. Highest number of spores was found under sunn hemp followed by sudangrass and lablab. Among the four cover crops, pearl millet had the lowest number of spore count.

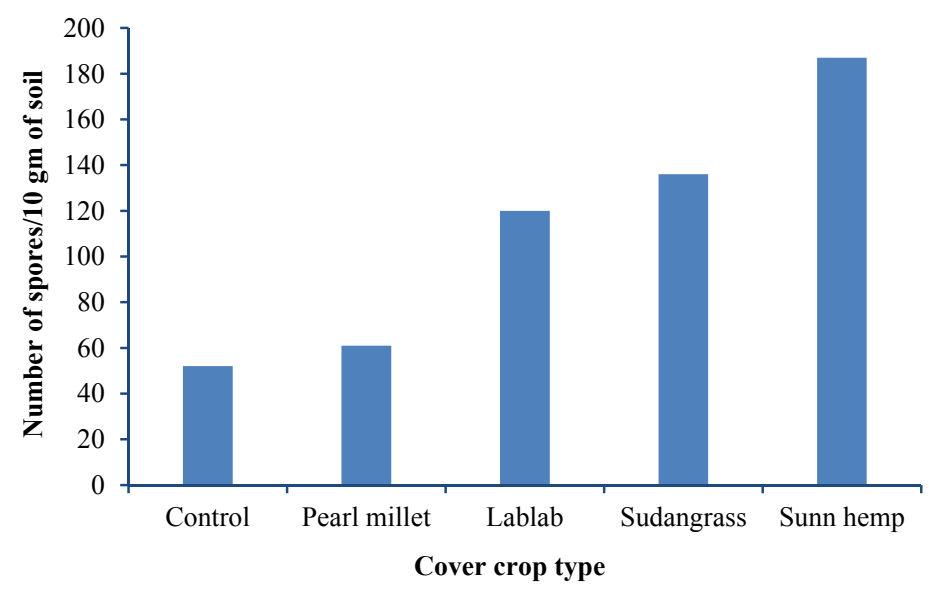

Figure 1. Number of mycorrhizal spores per 10 grams of soil under each cover crop

There was also a difference in the spore size among the different cover crops. Sunn hemp and sudangrass had 
generally bigger spores while the control and pearl millet generally had smaller spores with few large spores. 14 different species of mycorrhizal fungi were identified in the study from three different genera: Glomus, Aculospora and Gigaspora. The distribution of these spores varied among the different cover crops. Glomus was most dominant in the sunn hemp and lablab and a high density of Gigaspora occurred in the sudangrass treatment.

There was a strong positive correlation between the number of spores and soil magnesium $(r=0.96, p=0.0095)$ and boron concentration $(\mathrm{r}=0.92, \mathrm{p}=0.025)$. A strong negative correlation was seen between the number of spores and soil moisture $(r=-0.93, p=0.021)$ indicating that the number of mycorrhizal spores were higher in dry soils compared to wetter soils. However, there was no significant correlation between the total number of spores and soil organic matter, nitrate, or phosphorus concentration.

\subsection{Soil Nutrient Status}

Our results show that cover crop treatments had mixed results in changing the soil nutrient status (Table 2). All treatments increased soil organic matter, declining only in the control treatment. Similarly, concentration of copper and zinc also went up in the plots with cover crops while their concentration declined in the control treatment plots. Concentration of boron, calcium, magnesium, phosphorus, and potassium increased in all the treatments. Highest increases in boron concentration was observed in the lablab treatment, followed by the sunn hemp t. Similarly, sunn hemp resulted in the highest increase in the soil magnesium concentrations, followed by lab lab and pearl millet.

Table 2. Change in the soil nutrient status after each cover crop (in ppm). Numbers are calculated by subtracting the pre cover crop soil nutrient concentration from the post cover crop nutrient concentration.

\begin{tabular}{llllll}
\hline & Pearl Millet & Lablab & Sunn hemp & Sudan grass & Control \\
\hline Boron & 0.2 & 0.55 & 0.9 & 0.45 & 0.2 \\
Calcium & 1852 & 1406.5 & 1427 & 500 & 3360 \\
Copper & 0.6 & 0.2 & 0.4 & -0.1 & -2.3 \\
Iron & 0.1 & 0.1 & 0.15 & 0.15 & 0 \\
Magnesium & 24 & 28 & 35.5 & 13.5 & 27 \\
Manganese & -1 & -0.5 & 0.65 & -2.45 & -6.7 \\
Nitrate & 2 & -3 & 7.5 & 0.5 & 2 \\
OM\% & 0.45 & 0.87 & 1.46 & 1.08 & -0.48 \\
pH & 0.1 & 0.05 & 0 & 0 & 0.1 \\
Phosphorus & 9.9 & 19.2 & 19.3 & 15.35 & 6.8 \\
Potassium & 142 & 205.5 & 205.5 & 138.5 & 143 \\
Sulfur & 0.4 & -14.25 & -18.65 & -12.8 & -32.9 \\
Zinc & 0.6 & 0.5 & 0.6 & 0.25 & -5.3 \\
\hline
\end{tabular}

\section{Discussion}

The beneficial effects of cover crops on mycorrhizal fungi have been well documented (Galvez et al., 1995; Boswell et al., 1998; Douds et al., 2005). This study confirmed the potential of warm seasoncover crops in promoting native mycorrhizal fungi in subtropical organic farms. Our results indicate that over, cover crops can help improve the density and structure of mycorrhizal fungi. However, of the number of spores was not necesarrily associated with improved soil physical and chemical properties as tested in this study. While the number of mycorrhizal fungi spores was positively correlated with increases in soil magnesium and boron, here was a strong negative correlation between the fungal spore density and soil moisture. In addition, mycorrhizal fungi varied among the different cover crops. Glomus spp. was most commonly found in sunn hemp and lablab treatments, where higher densitties of Gigaspora occurred in the sudangrass treatment. Similar results of higher density of Glomus in soils with high magnesium concentration and high Gigaspora density in low soil magnesium concentration has been reported in previous studies (Schenck \& Siqueira, 1987; Gryndler, 1992). The overall diversity of mycorrhizal fungi, however, was similar for the different cover crops and was lower in the control treatment.

Soil organic matter is the major component of sustainable agriculture, and when growing vegetables and specialty 
crops, a soil high in organic matter is very desirable. Cover crops are known to increase soil organic matter and enhance the natural productivity and fertility of soil. In our study all the cover crops increased the soil organic matter compared to the control treatment where it decreased over the course of the experiment.Generally, grass cover crops are known to contribute more soil carbon than legumes (Hoorman, 2009). However, in this study, sudangrass contributed less organic matter compared to sunn hemp when measured after 4 weeks of incorporating cover crops into the soil. A possible reason for this could be the sudangrass had lignified when tilled and may not have fully decomposed in the soil because of its high C: $\mathrm{N}$ ratio (Wang \& Noite, 2010).

Sunn hemp resulted in highest nitrate concentration in the soil. However contrary to our expectation lablab, caused a decline in the soil nitrate. A possible explanation for this outcome could be the high density of weeds in the lablab plots relative to the other treatements. Similarly, sunn hemp also out performed other treatments in the conservation of phosphorous in the soil signaling its potential as a warm season cover crop to improve soil health in subtropical agroecosystems.

While cover-crop selection often depends on specific farm conditions and expected outcomes, this study shows that in this subtropical region, where the soils are alkaline and have high calcium concentration, cover-crops can facilitate a diversity of benefits associated with soil mycorrhizal fungi. More detailed analysis is required to calculate the total benefits, but if seed costs are low, soil rehabilitation with covercrops can be beneficial to farmers with only minor additional costs. In addition, in areas where farm rotations include non-mycorrhizal crops (such as kale and other brassicas) with mycorrhiza dependent crops such as peppers or other fruiting plants, incorporating cover crops in rotation could play an important role in increasing mycorrhizal inoculum potential and growth of subsequent mycorrhiza dependent crop.

\section{Acknowledgements}

This study was supported by the USDA-NIFA-ORG \#2013-28422-20954. Any reference to any vendor, product or services by trade name, trademark, or manufacturer or otherwise does not constitute or imply the endorsement, recommendation by the USDA or the University of Texas Rio Grande Valley. We thank Yahweh Organic Farm (Harlingen, Texas) as research participants in their farm, Frank Dirrigl, Department of Biology, UTRGV for letting using his lab supplies for the sample analysis. We also thank Amrita Singh for her help in sample processing.

\section{References}

Anonymous. (2003). Version, S.A.S. 9.0 [Computer Program]. Cary, NC: SAS Institute.

Barrios, E. (2007). Soil biota, ecosystem services and land productivity. Ecological Economics, 64(2), 269-285. http://dx.doi.org/10.1016/j.ecolecon.2007.03.004

Boswell, E. P., Koide, R. T., Shumway, D. L., \& Addy, H. D. (1998). Winter wheat cover cropping, VA mycorrhizal fungi and maize growth and yield. Agriculture, Ecosystems \& Environment, 67(1), 55-65. http://dx.doi.org/10.1016/S0167-8809(97)00094-7

Cheeke, T. E., Coleman, D. C., \& Wall, D. H. (Eds.). (2012). Microbial ecology in sustainable agroecosystems. CRC Press.

Douds Jr, D. D., Nagahashi, G., Pfeffer, P. E., Kayser, W. M., \& Reider, C. (2005). On-farm production and utilization of arbuscular mycorrhizal fungus inoculum. Canadian Journal of Plant Science, 85(1), 15-21. http://dx.doi.org/10.4141/P03-168

Galvez, L., Douds, D. D., Wagoner, P., Longnecker, L. R., Drinkwater, L. E., \& Janke, R. R. (1995). An overwintering cover crop increases inoculum of VAM fungi in agricultural soil. American Journal of Alternative Agriculture, 10(04), 152-156. http://dx.doi.org/10.1017/S0889189300006391

Gerdemann, J. W., \& Nicolson, T. H. (1963). Spores of mycorrhizal Endogone species extracted from soil by wet sieving and decanting. Transactions of the British Mycological Society, 46(2), 235-244. http://dx.doi.org/10.1016/S0007-1536(63)80079-0

Gryndler, M., Vejsadová, H., \& Vančura, V. (1992). The effect of magnesium ions on the vesicular-Arbuscular mycorrhizal infection of maize roots. New Phytologist, 122(3), 455-460. http://dx.doi.org/10.1111/j.1469-8137.1992.tb00073.x

Hoorman, J. J. (2009). Using cover crops to improve soil and water quality. Lima, Ohio: Agriculture and Natural Resources, The Ohio State University Extension.

Johnson, N. C., Wilson, G. W. T., Bowker, M. A., Wilson, J. A., \& Miller, R. A. (2010). Resource limitation is a 
driver of local adaptation in mycorrhizal symbioses. PNAS, 107, 2093-2098. http://dx.doi.org/10.1073/pnas. 0906710107

Kabir, Z., \& Koide, R. T. (2000). The effect of dandelion or a cover crop on mycorrhiza inoculum potential, soil aggregation and yield of maize. Agriculture, Ecosystems \& Environment, 78(2), 167-174. http://dx.doi.org/ $10.1016 / \mathrm{S} 0167-8809(99) 00121-8$

Khade, S. W., \& Rodrigues, B. (2009). Applications of arbuscular mycorrhizal fungi in agroecosystems. Tropical and Subtropical Agroecosystems, 10, 337-354. Retrieved April 25, 2016, from http://www.redalyc.org/articulo.oa?id=93912996003

Marschner, H., \& Dell, B. (1994). Nutrient uptake in mycorrhizal symbiosis. Plant Soil, 159, 89-102.

Miller, M. H., McGonigle, T. P., \& Addy, H. D. (1995). An economic approach to evaluate the role of mycorrhizas in managed ecosystems. Plant and Soil, 159, 27-35

Naidu, R., \& Rengasamy, P. (1993). Ion interactions and constraints to plant nutrition in Australian sodic soils. Soil Research, 31(6), 801-819. http://dx.doi.org/10.1071/SR9930801

Pineda, A., Zheng, S. J., van Loon, J. J., Pieterse, C. M., \& Dicke, M. (2010). Helping plants to deal with insects: the role of beneficial soil-borne microbes. Trends in Plant Science, 15(9), 507-514. http://dx.doi.org/10.1016/j.tplants.2010.05.007

Schenck, N. C., \& Pérez, Y. (1988). Manual for the identification of VA mycorrhizal fungi (p. 250, 2nd ed.). Synergistic Publications, Gainesville, Florida.

Schenck, N. C., \&Siqueira, J. O. (1987). Ecology of VA mycorrhizal fungi in temperate agroecosystems. Proc. of 7th NACOM-Mycorrhizae in the Next Decade, Practical Applications and Research Priorities (pp. 2-4).

Soka, G., \& Ritchie, M. (2014). Arbuscular mycorrhizal symbiosis and ecosystem processes: Prospects for future research in tropical soils. Open Journal of Ecology, 4(1), 11-22. http://dx.doi.org/10.4236/oje.2014.41002

Storez, B. (2011). Vegetable crop of the Lower Rio Grande Valley. Texas AgriLIFE Extension Service, Texas A\&M UniversitySystem. Retrieved April 25, 2016, from http://hidalgo.agrilife.org/files/2012/05/Vegetable -Planting-Guide1.pdf

Van Der Heijden, M. G., \& Scheublin, T. R. (2007). Functional traits in mycorrhizal ecology: their use for predicting the impact of arbuscular mycorrhizal fungal communities on plant growth and ecosystem functioning. New Phytologist, 174(2), 244-250. http://dx.doi.org/10.1111/j.1469-8137.2007.02041.x

Van Der Heijden, M. G., Streitwolf-Engel, R., Riedl, R., Siegrist, S., Neudecker, A., Ineichen, K., \& Sanders, I. R. (2006). The mycorrhizal contribution to plant productivity, plant nutrition and soil structure in experimental grassland. New Phytologist, 172(4), 739-752. http://dx.doi.org/10.1111/j.1469-8137.2006.01862.x

Wang, G. S., \&Noite, K. (2010). Summer cover crop use in Arizona vegetable production systems. University of Arizona Extension. Retrieved April 25, 2016, from http://extension.arizona.edu/sites/extension.arizona.e du/files/pubs/az1519.pdf

Wang, K. H., McSorley, R., Marshall, A., \& Gallaher, R. N. (2006). Influence of organic Crotalaria juncea hay and ammonium nitrate fertilizers on soil nematode communities. Applied Soil Ecology, 31(3), 186-198. http://dx.doi.org/10.1016/j.apsoil.2005.06.006

\section{Copyrights}

Copyright for this article is retained by the author(s), with first publication rights granted to the journal.

This is an open-access article distributed under the terms and conditions of the Creative Commons Attribution license (http://creativecommons.org/licenses/by/4.0/). 